\title{
Spike-timing theory of working
}

\author{
Botond Szatmáry, Eugene M Izhikevich \\ From Twentieth Annual Computational Neuroscience Meeting: CNS*2011 \\ Stockholm, Sweden. 23-28 July 2011
}

It is commonly assumed that long-term memory is represented by patterns of synaptic connections within groups of neurons and that memory recall corresponds to an activation of a group triggered, e.g., by a sensory stimulus. Sustained spiking activity of one or a few selected long-term memory representations is believed to be the neural correlate of working memory.

The capacity of working memory is referred to as being the number of neuronal groups that could be maintained active at the same time. This short-term memory capacity is, for example, thought to be seven plus or minus two items for ordered lists. We distinguish the short-term capacity from long-term memory capacity or repertoire, which is the large number of neuronal groups required to store many distinct memories formed by past sensory experience.

We propose [1] a mechanism for working memory that allows for a greatly expanded long-term memory capacity, and we demonstrate how this mechanism can simultaneously maintain in working memory a few items out of this huge repertoire (which is far greater than the number of neurons).

We assume that (i) the groups of neurons representing long-term memories are largely overlapping and (ii) neurons (within a group) are capable of exhibiting precise firing patterns, so different representations are distinguished not only by which neurons fired, but also by their exact spiking patterns. This is in contrast with previously suggested mechanisms of working memory, where the spike-timing nature of neuronal activity is ignored and the models' explanatory power is limited to systems having small repertoires of long-term memories represented by, e.g., carefully selected non-overlapping populations of neurons.

Using associative short-term synaptic plasticity in the form of short-term STDP, we demonstrate that a few

* Correspondence: botond.szatmary@braincorporation.com Brain Corporation, San Diego, CA 92121, USA neuronal groups can be simultaneously selected to transiently be part of working memory, i.e., show elevated and precise firing activity for seconds after initial activation.

Our theory explains the relationship between precise spikes and slowly changing firing rates of neurons engaged in active maintenance of working memory, and it points to the connection between working memory and perception of elapsed time on the order of seconds.

Published: 18 July 2011

Reference

1. Szatmáry B, Izhikevich EM: Spike-Timing Theory of Working Memory. PLoS Comput Biol 2010, 6(8):e1000879, doi:10.1371/journal.pcbi.1000879.

doi:10.1186/1471-2202-12-S1-O3

Cite this article as: Szatmáry and Izhikevich: Spike-timing theory of working. BMC Neuroscience 2011 12(Suppl 1):O3.

Submit your next manuscript to BioMed Central and take full advantage of:

- Convenient online submission

- Thorough peer review

- No space constraints or color figure charges

- Immediate publication on acceptance

- Inclusion in PubMed, CAS, Scopus and Google Scholar

- Research which is freely available for redistribution

Submit your manuscript at www.biomedcentral.com/submit

\section{() Biomed Central}

\section{Biomed Central}

(c) 2011 Szatmáry and Izhikevic; licensee BioMed Central Ltd. This is an open access article distributed under the terms of the Creative Commons Attribution License (http://creativecommons.org/licenses/by/2.0), which permits unrestricted use, distribution, and reproduction in any medium, provided the original work is properly cited. 